\title{
Process Contribution to the Time-Varying Residual Circulation in Tidally Dominated Estuarine Environments
}

\author{
Jennifer M. Brown • Rodolfo Bolaños • \\ Alejandro J. Souza
}

Received: 24 August 2012 /Revised: 30 October 2013 / Accepted: 18 November 2013 / Published online: 15 December 2013

(C) The Author(s) 2013. This article is published with open access at Springerlink.com

\begin{abstract}
In tide-dominated environments, residual circulation is the comparatively weak net flow in addition to the oscillatory tidal current. Understanding the 3D structure of this circulation is of importance for coastal management as it impacts the net (longer term and event-scale) transport of suspended particles and the advection of tracer quantities. The Dee Estuary, northwest Britain, is used to understand which physical processes have an important contribution to the time-varying residual circulation. Model simulations are used to extract the time-varying contributions of tidal, riverine (baroclinicity and discharge), meteorological, external and wave processes, along with their interactions. Under hypertidal conditions, strong semi-diurnal interaction within the residual makes it difficult to clearly see the effect of a process without filtering. An approach to separate the residual into the isolated process contribution and the contribution due to interaction is described. Applying this method to two hypertidal estuarine channels, one tide dominant and one baroclinic dominant, reveals that process interaction can be as important as the sub-tidal residual process contributions themselves. The time variation of the residual circulation highlights the impact of different physical process components at the event scale of tidal conditions (neap and spring cycles) and offshore storms (wind, wave and surge influence). This gives insight into short-term deviation from the typical estuarine residual. Both channels are found to react differently to the same local conditions, with different short-term change in process dominance during events of high and low energy.
\end{abstract}

Communicated by Arnoldo Valle-Levinson

J. M. Brown $(\bowtie) \cdot$ A. J. Souza

National Oceanography Centre, Joseph Proudman Building, 6

Brownlow Street, Liverpool L3 5DA, UK

e-mail: jebro@noc.ac.uk

R. Bolaños

DHI, Agern Allé 5, 2970 Hørsholm, Denmark
Keywords Dee Estuary · Tide surge stratification ·

POLCOMS-GOTM-WAM · Coastal management · Residual circulation $\cdot$ Hypertidal interaction

\section{Introduction}

This research continues from earlier studies of the 3D circulation within the channels of this hypertidal estuary system (Bolaños et al. 2013) and coastal wave impact across Liverpool Bay (Brown et al. 2011). Bolaños et al. (2013) focused on the time-varying stratification and turbulence profiles, in addition to the classification of the different estuarine channels. Here attention is given to the time-varying residual estuarine circulation, which is defined as the instantaneous circulation remaining once the harmonic tide has been removed from the total circulation. The cumulative effect of the event-scale residual circulation within an estuary will influence the net longer term transport of particles, such as sediment, microorganisms and biogeochemical particles (nutrients and gasses, e.g. carbon), which are suspended or dissolved in the water column, and the advection of tracer quantities, such as temperature and salinity. Understanding the long-term transport pathways and the event-scale contribution is crucial for sustainable management. Residual circulation is of particular interest as it can determine the sediment pathways controlling long-term morphological evolution of an estuary system (Prandle 2004).

Within coastal areas, the tides can interact with variable bathymetry, creating complex residual flow (e.g. Aubrey and Speer 1985; Wang et al. 2009) due to varying depths and bottom friction (e.g. Huthnance 1981; Warner et al. 2004), tidal asymmetries (e.g. Boon and Byrne 1981), inter-tidal flats (e.g. Bowers and Al-Barakati 1997) and channel constraint (e.g. Brown and Davies 2010). The longitudinal density gradient within an estuary creates a gravitational circulation 
(Pritchard 1952; Hansen and Rattray 1965), which moves freshwater seaward in the upper water column and salty water landward near the bed; this is particularly important for the net along-channel transport. At times of stratification, the strength of this circulation can be increased. Variability in the vertical structure of the residual circulation causes horizontal transport of positively buoyant particles in the upper flow and negatively buoyant particles in the bottom flow at different rates (Burchard and Hetland 2010). This residual is further complicated by tidal straining (Simpson et al. 1990) and wind straining (Chen et al. 2009) of the vertical density profile, which can modify the strength of the estuarine circulation. At the coast, wave-induced currents can also cause an event-scale residual flow due to mass transport in the bottom boundary layer (Longuet-Higgins 1958) and radiation stress (Longuet-Higgins and Stewart 1964; Longuet-Higgins 1970). For both tidal and surface waves, Stokes' drift can influence the net flow, as well as wind-driven circulation. Depending on the frequency of storm events, both wave and wind circulation may contribute to the long-term transport, or create seasonal patterns in the residual.

Here we investigate the time-varying process contribution to the residual flow within two different channel regimes of the Dee Estuary, situated in Liverpool Bay northwest Britain (Fig. 1). The residuals in these channels represent a tidally dominant and baroclinically dominant system (Bolaños et al. 2013). This estuary has contrasting coastlines: one of industrial importance, the other supporting natural habitat. Human intervention within the estuary system, e.g. river canalisation, has led to siltation making the upper estuary un-navigable (Pye 1996). Improved understanding of the sediment pathways within this estuary is therefore of importance for longterm management to sustain the industrial usage and maintain the natural habitat. Here, the 3D circulation influencing sediment transport is made up of the tide and a residual component. A combination of processes and their interactions generate the residual, such as storm surge, atmospheric forcing, tides, waves, freshwater input and river flow. These processes have been well modelled for the Dee (see Bolaños et al. 2013 and Brown 2010), enabling confident assessment of their influence on the long-term time-mean residual circulation. In the present study, a detailed analysis of the time-varying residuals is performed in order to understand the time and depth varying pulses induced for different processes. The modelled time-averaged residual circulation has been validated by Bolaños et al. (2013), while the time-varying residual elevation has been validated by Brown et al. (2012). Here, the modelling system is validated and implemented for selected processes to investigate the event-scale importance of their isolated time-varying contributions to the residual circulation. Using filtering techniques, the strength of the sub-tidal and intra-tidal contribution to the residual is assessed.
In the next section ("The Study Location and Conditions"), the Dee Estuary is described along with the conditions during the period of the study. This is followed in the section "Model Setup and Validation" by a description of the modelling system and its validation. An approach to separate the residual components of interest is described along with a filtering method to remove tidal interaction. The isolated residual processes and their interactions are presented in the "Results" section. These time-varying results are used to compare competitive processes to identify how each generates a short-term event-scale contribution to the residual circulation. Following the "Discussion" section, it is concluded in the final section that in a tidally dominant channel, under low energy wave and wind conditions, low river flow can generate short-term baroclinic dominance within the residual circulation. Storm impact is found to have a strong influence at the eventscale during extreme conditions. The intra-tidal process residual for this hypertidal estuary is shown to be comparable in magnitude to the sub-tidal process residual. These findings highlight that the short-term (event-scale) residual pathways can differ to the dominant long-term process (Brown et al. 2014). This may be important for net sediment dynamics, since the volume flux can be greatly intensified during certain (storm or river) events.

\section{The Study Location and Conditions}

\section{The Dee Estuary}

The Dee is a hypertidal estuary with semi-diurnal tides reaching a maximum range of $\sim 10 \mathrm{~m}$, creating a vast expanse of inter-tidal shoals that form a network of tidal channels, within which current speeds can reach $1.2 \mathrm{~m} \mathrm{~s}^{-1}$ (Fig. 2a, b). The estuary experiences low river input (Fig. 2e), the mean flow at Manley Hall (a gauging station run by the Environment Agency) between 1937 and 2011 was $31 \mathrm{~m}^{3} \mathrm{~s}^{-1}$. Close to the estuary mouth (Fig. 1), two main channels exist, the Welsh Channel to the west and the Hilbre Channel to the east (Bolaños et al. 2011). The waves within the estuary channels are able to reach $2.2 \mathrm{~m}$ (Fig. 2c). Typical estuarine stratification close to the mouth occurs in the channels either during (and then persists, Hilbre Channel) or soon after (Welsh Channel) low tide, even though tidal mixing is strong and river discharge is weak. Both channels are strongly influenced by strain-induced stratification (Simpson et al. 1990). This is confirmed by calculating the Simpson number $\left(\sim 1.45 \times 10^{-3}\right.$, Bolaños et al. 2013, equivalent to a $R i_{x}$ of $\sim 0.6$, Monismith et al. 1996), which is analogous to the horizontal Richardson number, and the Strouhal number $(\sim 5 \times$ $10^{-4}$, Bolaños et al. 2013, equivalent to a Stokes number of $\sim 100$, Souza 2013). These values suggest that straining of strongly stratified conditions occurs when compared with Burchard (2009). As shown by the $R i_{x}$ number $(>0.25)$, even though the river flow is much weaker than the tidal flow, the baroclinic influence can be important close to the estuary mouth and tidal 
Fig. 1 The local Liverpool Bay model domain, northwest Britain. The bottom panel shows the monitoring locations (triangles) and the TRIAXYS buoy (square) within the Dee Estuary

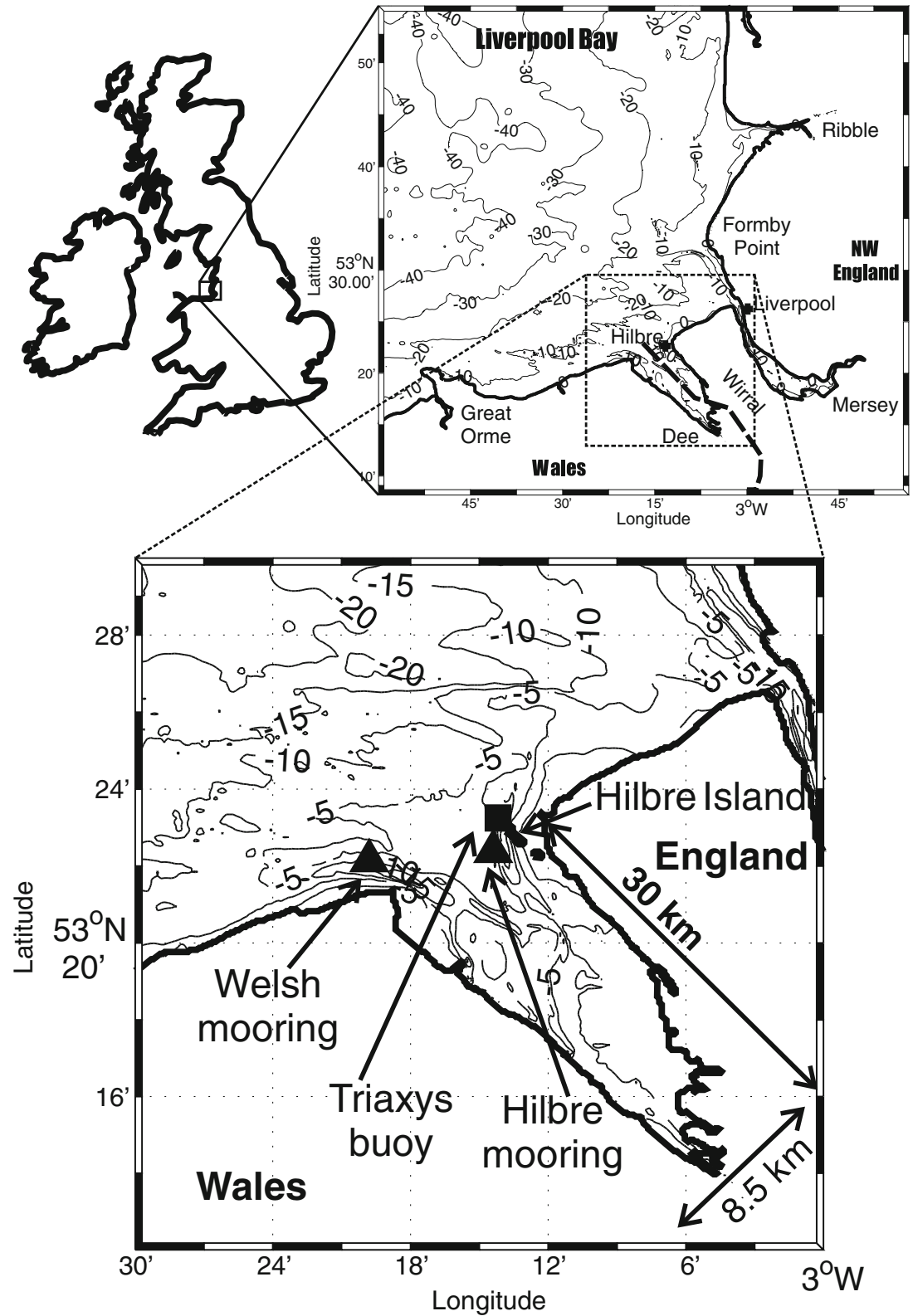

straining can be present. Evaluation of this estuary's dynamics (Bolaños et al. 2013) has shown that within this hypertidal system with weak river flow the channels display different dominant behaviours representative of barotropic (Welsh Channel) and baroclinic (Hilbre Channel) dominant environments. The time-mean patterns consist of a vertical two-layer system in the Hilbre Channel and a horizontal two-layer system in the Welsh Channel. Even during a period of wind-wave influence, the baroclinic two-layer system still persists in the Hilbre Channel (Brown et al. 2014). The cumulative effect of the time-varying process contribution to the long-term mean spatial pattern in residual circulation is studied further by Brown et al. (2014). The Kelvin number for the estuary during this study period is 0.97 , using the mean density in the channels at the mouth. A value greater than 1 means the Coriolis effect is important, influencing the baroclinic circulation. This value suggests a moderate influence of the Coriolis effect, explaining why the river influence is dominant in the Hilbre Channel, as the river flow is diverted toward the right of the estuary. This dominance is strengthened by the fact that the cross-sectional average tidal residual is ebb dominant in Hilbre Channel and flood dominant in the Welsh Channel (Brown et al. 2014).

\section{The Study Period}

The time-varying residual circulation is studied at two locations near the mouth of the Dee Estuary. These two points represent the position of instrument deployment for a 25-day 


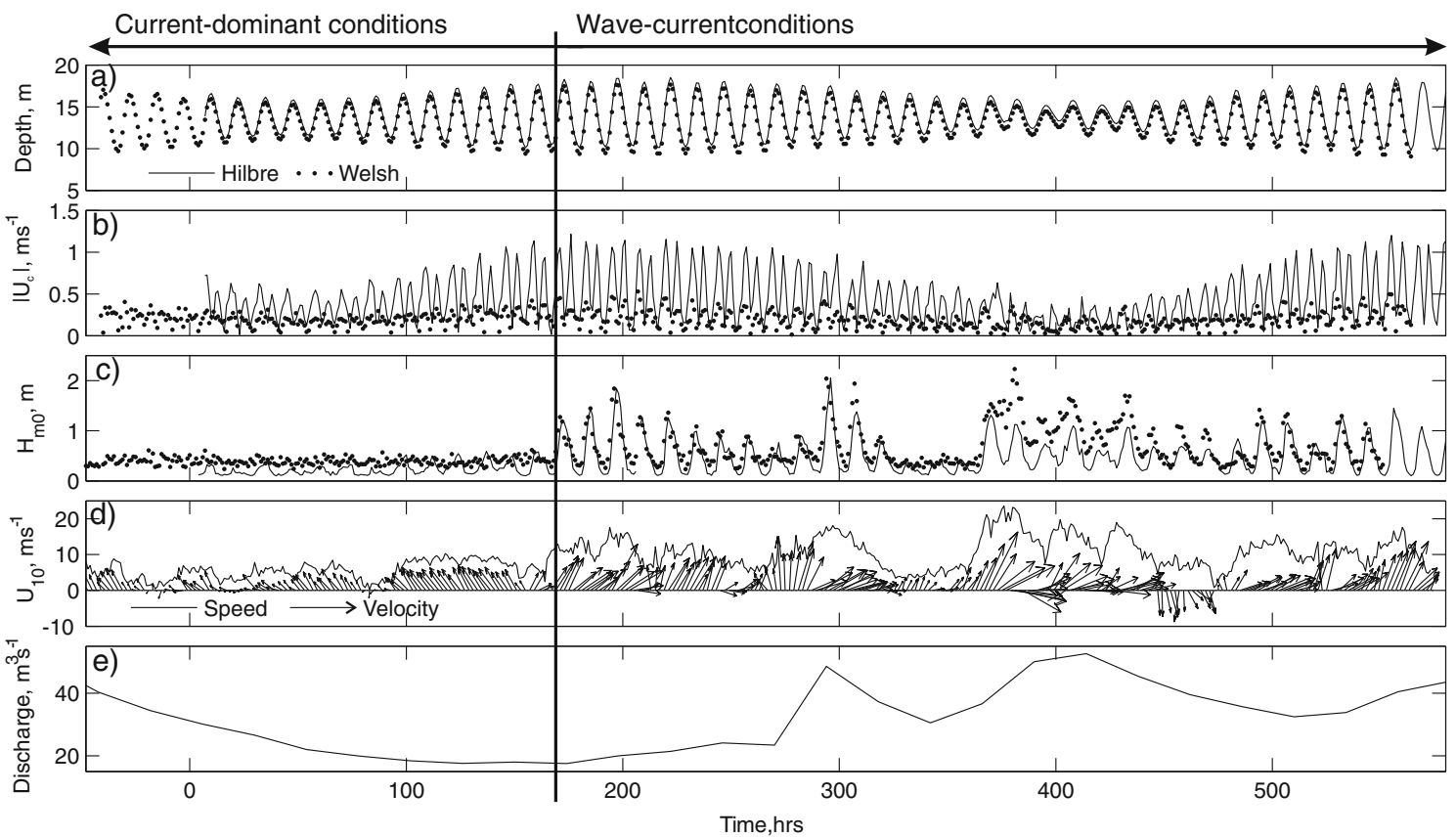

Fig. 2 The observed conditions during the study period: a depth measured by the mooring pressure sensors, $\mathbf{b}$ current speed measured at $0.35 \mathrm{~m}$ above the bed in the Welsh Channel by an acoustic Doppler velocimeter (ADV) and at $3.0 \mathrm{~m}$ above the bed in the Hilbre Channel by an acoustic Doppler current profiler (ADCP), c significant wave height measured by pressure sensors on the moorings, $\mathbf{d}$ wind conditions at $10 \mathrm{~m}$ above the surface recorded at the Hilbre Island (located in Fig. 1) met station and $\mathbf{e}$ the available daily average river discharge for the Dee. The data are shown for both the Hilbre (solid line) and Welsh (dotted line) channels. The time axis starts at 06:00 12th February with a 48-h delay between the deployment of the Welsh and Hilbre instruments. Time $0 \mathrm{~h}$ represents the start of this study when data are available for both channels, 06:00 14th February. Some data loss for Hilbre occurs during deployment. The vertical line represents when the waves were initiated within the model

the two estuary channels are compared to see how different processes influence a barotopic-dominant and baroclinicdominant channel. ous studies (Bolaños et al. 2013) for validation purposes. Details of the instruments deployed are given by Bolaños and Souza (2010). This period includes calm current-dominant conditions, prior to the 21 st February ( $<168$ h, Fig. $2 \mathrm{a}-\mathrm{c}$ ), followed by wave and current conditions, which incorporate an extreme storm event at neap tide creating wave dominant conditions on the 29th February 2008 (359-447 h, Fig. 2c-e). These changing conditions are therefore appropriate to investigate time-varying residuals using numerical experiments. The use of time-series data at single points enables high-frequency time variation (hourly) to be studied, although the spatial variability is not captured. Patterns in the spatial variability of the residual circulation across and along these channels are detailed by Brown et al. (2014). River discharge reached $52 \mathrm{~m}^{3} \mathrm{~s}^{-1}$ with a mean discharge of $32 \mathrm{~m}^{3} \mathrm{~s}^{-1}$ during the study, so is considered as weak (Fig. 2e). The Hilbre Channel experienced greater freshwater influence than the Welsh Channel (located in Fig. 1), creating different tidally interactive two-layer circulation within the channels (Bolaños et al. 2011). Initial studies (Brown et al. 2012) have found that residual elevations external to Liverpool Bay and local meteorological forcing are important in influencing the residual water levels within this estuary. Here we investigate the importance of temporal variability in local and external processes on the $3 \mathrm{D}$ residual circulation at the estuary mouth. The findings in

\section{Model Setup and Validation}

\section{The Modelling System}

The 3D circulation was hindcast by the baroclinic--barotropic Proudman Oceanography Laboratory Coastal Ocean Modelling System (POLCOMS, Holt and James 2001) coupled to the General Ocean Turbulence model (GOTM, Umlauf and Burchard 2005). A further coupling to the WAve Model (WAM, Komen et al. 1994), modified for coastal applications (see Monbaliu et al. 2000) and the generation of radiation stress (using Mellor 2003, 2005), enabled 3D wave-induced currents and enhanced bottom friction and surface roughness to be included. The modelling system was coupled such that a two-way exchange of information occurred between the component models and was configured to include wetting and drying, making it apt for this estuarine application. The wave coupling was initiated on the $21 \mathrm{st}$ February 00:00, when the conditions were no longer considered calm and the waves exceed $0.6 \mathrm{~m}$ (>168 h, Fig. 2c), to 
reduce computational cost. No wave-induced residual is therefore shown in later figures during the calm period. Prior to this time, wave activity is assumed to be minimal within the estuary. Details of the modelling system setup and validation of this period confirming this approach is acceptable are given by Bolaños et al. (2013). Previous studies have also shown it to give good multi-year tide-surge hindcast across the eastern Irish Sea (Brown et al. 2010) and within Liverpool Bay (Brown et al. 2011).

Operational atmospheric forcing from the UK Met Office was used to drive the local Liverpool Bay model. The full set of $\sim 12 \mathrm{~km}$ resolution atmospheric conditions (three hourly air temperature and specific humidity, with hourly pressure and $10 \mathrm{~m}$ wind components) is used to include air-sea heat and momentum fluxes. Freshwater input is considered using daily mean gauged discharge at all available river sources around the Irish Sea. The offshore (Liverpool Bay) model boundary (Fig. 1) was forced by the 1.8-km Irish Sea model (see Brown et al. 2010), so waves and surge generated externally to Liverpool Bay over the continental shelf were able to propagate into the study region. The local wave and surge generation is due to the wind acting over the fetches within the model domain and atmospheric pressure having an inverse barometer effect. To enable a barotropic-baroclinic Irish Sea simulation, boundary conditions are prescribed by the $\sim 12-\mathrm{km}$ operational European continental shelf surge model and 3D Atlantic margin model. This then provides the external tide-surgebaroclinic or tide-only current field and elevation boundary conditions every 30 min to the Liverpool Bay model, while the wave conditions are updated hourly.

\section{Model Validation}

The depth-averaged time-varying residual current components for the default model setup (PG) have been compared with observation (Fig. 3a, b). Taking the depth average enables the full water column to be considered at each time instance and does not incur problems relating to the volume conservation of sigma coordinates when time-averaged. The comparison is performed using the ADCP measurements in the Hilbre Channel for the full period of observation at the fixed mooring. Both the model results and observations are filtered (see "Model Validation" section) to obtain the subtidal residual. This technique causes a loss of data at the ends of the time series. It is clear that the model overpredicts the depth-mean currents and has less accuracy during the stormier period (around hour 300). Generally, the model shows less fluctuation than the observations. The wave conditions are also compared using a wave buoy deployed in the Hilbre Channel close to the ADCP mooring (Fig. 1). The modulation in the wave properties over the tidal cycle in response to depth change is captured (Fig. 3c, d), while the model tends to slightly underpredict the magnitude. Standard error metrics
( $R^{2}$ coefficient of determination as used by Brown et al. 2013a; RMS error and mean bias as used by Brown et al. 2013b; and the Willmott et al. (1985) index of agreement) are presented in Table 1 for both the residual circulation and waves. Further validation within the bay has been performed on the long-term residual circulation (Polton et al. 2013). The bias in residual circulation near the Dee Estuary was found to be related to the complex dynamics (misaligned horizontal density gradient and surface slope) and shallow depths relative to the Ekman layer. The shape of the time-averaged vertical residual circulation profile (validated by Bolaños et al. 2013) is more accurate in the major channel axis component. The profile accuracy is sensitive to both baroclinic and atmospheric forcing, which both have limited accuracy as these forcing conditions are generated from the best available large-scale model data and limited (daily averaged) river records. The residual elevation (validated by Brown et al. 2012) does accurately respond to atmospheric forcing, capturing storm events, while the local processes within the estuary contribute little to the residual elevation. The values in Table 1 are therefore considered to be acceptable, since it is difficult to accurately predict residual flow within this complex system with the considered model physics. Since observations in the Welsh Channel are at a single depth below the first model sigma level, only the Hilbre Channel has been used for comparison, since this is the more complex channel with baroclinic influence the model is expected to perform as well, if not better, in the tidally dominant channel.

\section{Methods of Residual Circulation Extraction}

In hypertidal estuaries, the tide has a strong modulating influence on the other non-tidal physical processes, not only due to fast currents $\left(\sim 1.2 \mathrm{~m} \mathrm{~s}^{-1}\right.$ during spring tide in the Dee, Fig. 2b), but also due to the wetting and drying of banks, which modifies the bathymetric cross-sectional estuary profile. The model can be used to simulate circulation due to userchosen inputs, for example whether the atmospheric forcing is turned on or not in the model. In this model application, the physical processes available for user selection are as follows: meteorological forcing (M), baroclinicity (B), river flow (R), external residual $(\mathrm{E})$, tides $(\mathrm{T})$ and waves $(\mathrm{W})$. Filtering methods are also applied to the model data to remove all energy at tidal frequencies to isolate the tidally interactive residual component. Here the Chebyshev type II filter is used as a low-pass filter with a stop-band of $26 \mathrm{~h}$ and a pass-band of $30 \mathrm{~h}$ to remove all energy at tidal frequencies. A standard 3-dB pass-band amplitude was applied with a stop-band attenuation of $30 \mathrm{~dB}$, which is an attenuation factor of 1,000 . This leaves only the low-frequency ( $\geq 30 \mathrm{~h}$, sub-tidal) residual without any tidal energy or tidal interaction, which is removed as it has a similar frequency to the tide. Tidal harmonics with a period $\geq 30 \mathrm{~h}$ will not be removed by this filter design, but within an 


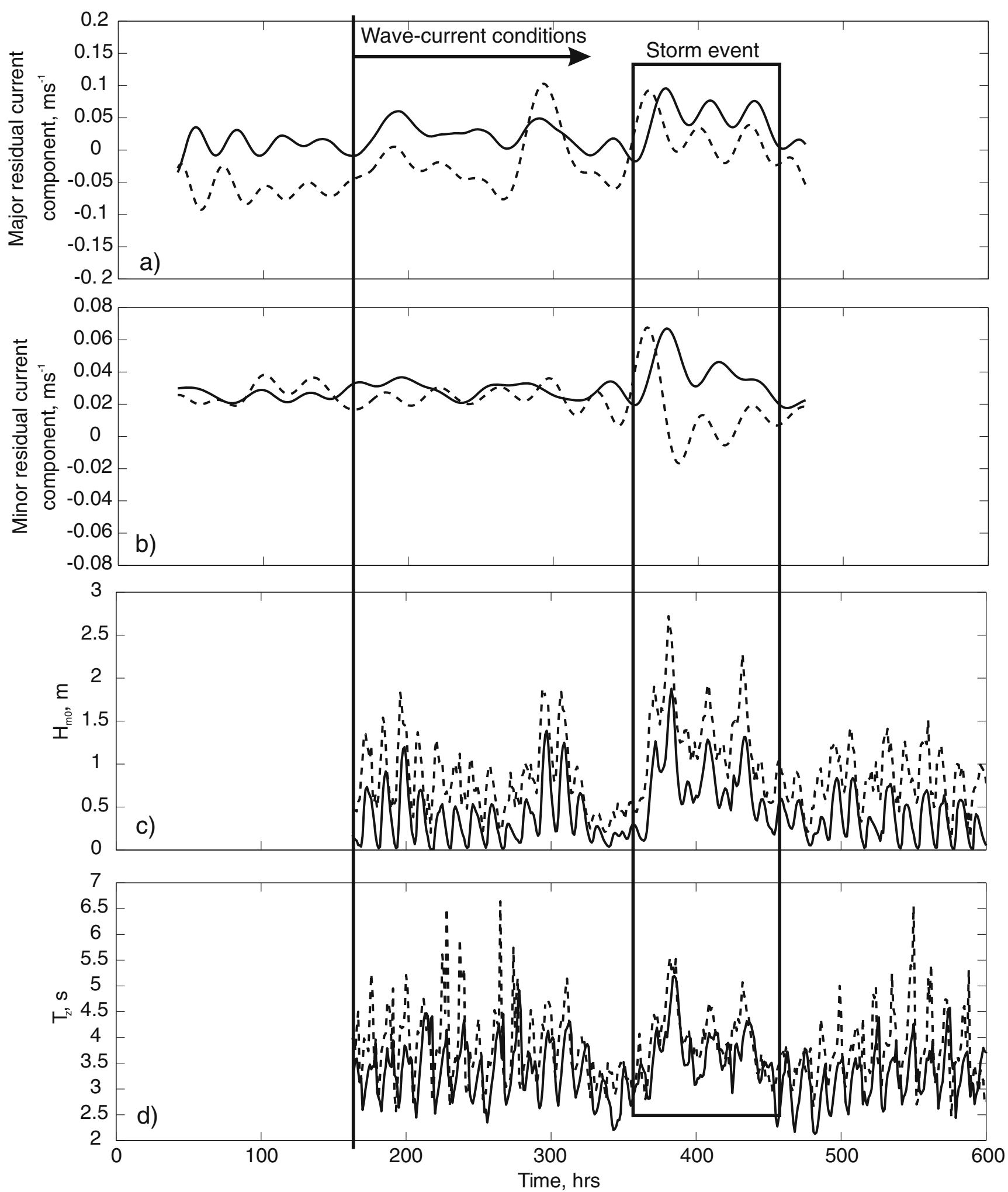

Fig. 3 Comparison of the modelled POLCOMS-GOTM and observed ADCP depth-averaged time-varying filtered residual velocity at the Hilbre mooring for $\mathbf{a}$ the major and $\mathbf{b}$ the minor channel axis current components. The WAM modelled wave conditions of $\mathbf{c}$ height and $\mathbf{d}$ period are compared with the Hilbre TRIAXYS buoy recordings, for the stormy period ( $>21$ st February). The time axis marks the full study period, 14th February 2008 06:00-9th March 2008 12:00. The solid lines represent model data and the dashed lines observation. The vertical line represents when the waves were initiated within the model and the box highlights the extreme storm event 
Table 1 Error metric values of the $R^{2}$, RMS error, mean bias and index of agreement, for the depth-averaged time-varying residual current components and time-varying wave conditions in the Hilbre Channel

\begin{tabular}{lllll}
\hline $\begin{array}{l}\text { Error } \\
\text { metric }\end{array}$ & $\begin{array}{l}\text { Along-channel } \\
\text { residual } \\
\text { current }\end{array}$ & $\begin{array}{l}\text { Cross-channel } \\
\text { residual } \\
\text { current }\end{array}$ & $\begin{array}{l}\text { Wave } \\
\text { height }\end{array}$ & $\begin{array}{l}\text { Wave } \\
\text { period }\end{array}$ \\
\hline$R^{2}$ & 0.26 & 0.93 & 0.75 & 0.34 \\
RMS error & $0.06\left(\mathrm{~m} \mathrm{~s}^{-1}\right)$ & $0.02\left(\mathrm{~m} \mathrm{~s}^{-1}\right)$ & $0.52(\mathrm{~m})$ & $0.73(\mathrm{~s})$ \\
Mean bias & $0.05\left(\mathrm{~m} \mathrm{~s}^{-1}\right)$ & $0.01\left(\mathrm{~m} \mathrm{~s}^{-1}\right)$ & $-0.47(\mathrm{~m})$ & $-0.45(\mathrm{~s})$ \\
$\begin{array}{c}\text { Index of } \\
\text { agreement }\end{array}$ & 0.56 & 0.29 & 0.71 & 0.67 \\
\hline
\end{tabular}

estuary environment their contribution is expected to be small. A two-way filtering process was applied so no phase shift occurred in the residual; however, the start and end of the residual cannot be accurately obtained, hence a shorter time series is later presented. When applied to the total modelled current velocity, more data are lost to filter error, at the ends of the time series, than when applied to the weaker residual current velocities obtained from model simulations. This is because the length of the erroneous period is a percentage of the input signal magnitude. Later figures for the filtered tidal and total current simulations are therefore shorter than those for the filtered (much weaker) residual current. This filter setup has previously been shown to successfully remove the tidal energy within surface elevations compared with harmonic tidal analysis methods within this estuary (Brown et al. 2012), so has been used again in this study.

Here the Liverpool Bay model calculates the current field at ten vertical levels, represented by sigma coordinates. This has been extracted at the locations of two instrumented fixed moorings deployed in the main tidal channels close to the estuary mouth for this study. Each model simulation within this study has the external boundary conditions prescribed by the Irish Sea model and includes Coriolis. For tide only, no atmospheric or riverine forcing is considered in the modelling systems. For the other reduced physics simulations, different component processes are turned off within the Liverpool Bay model, and these components included the following: river flow, baroclinic fields (temperature and salinity gradients), atmospheric forcing and waves. In this model application, the classical density-driven flow and straining properties are classified together as the baroclinic processes. The model is therefore coupled as POLCOMS-GOTM-WAM (PGW) or POLCOMS-GOTM (PG) to consider the following processes in the most computationally efficient way: meteorological forcing $(\mathrm{M})$, baroclinicity (B), river flow (R), external residual (E), tides (T) and waves (W). Meteorological forcing (M) represents surface heat and momentum fluxes due to wind, atmospheric pressure and solar heating. Baroclinic processes refer to the temperature and salinity fields setting up density gradients within the model domain. These gradients are generated by river inputs and surface heating. Baroclinicity (B) is included when the time-varying spatial temperature and salinity (density) gradients are enabled within the model. Rivers provide a volume flow rate of freshwater. They can be considered without baroclinicity to provide an additional source of volume flow rate only $(\mathrm{R})$. The term 'external residual' is used to describe the sub-tidal circulation generated across the Irish Sea that influences the local model domain of Liverpool Bay through boundary forcing. The nontidal external residual (E) is obtained by removing the tide and the locally generated sub-tidal residuals from the total sub-tidal circulation. In the model, tides $(\mathrm{T})$ are simulated by 15 constituents and shallow water processes are able to influence the propagation of the tidal wave into the estuary. Waves generated over fetches across the Irish Sea enhance both the bottom friction and surface roughness, in addition to generating wave-driven currents within the circulation model.

Prior to any processing, the modelled and observed total velocity components (east and north) were rotated to obtain the major and minor channel axis components (along- and across-channel). The rotation was applied separately to the observation and model to prevent discrepancies in bathymetry affecting the rotation. Rotation was applied to each vertical level separately. The largest difference in the rotation angle calculated for each model level and for the depth-averaged velocity was negligible $\left( \pm 0.7^{\circ}\right.$ in the Hilbre Channel). The same angle of rotation, calculated for the reference barotropic-baroclinic simulation (PG_MBRET), was applied to each model simulation for consistency.

The results presented consider the total residual circulation and its component parts, a sub-tidal ( $\geq 30 \mathrm{~h}$ period) processdriven component and an interactive component due to intratidal $(<30 \mathrm{~h}$ period) process interaction for all, $i$, processes modelled:

$$
\begin{aligned}
\text { total residual }= & \sum_{\mathrm{i}}(\text { sub-tidal process residual } \\
& + \text { intra-tidal process residual })
\end{aligned}
$$

From the model simulation, the full sub-tidal residual for all processes can be obtained by filtering:

full sub-tidal residual $=<$ full simulation $>$

where $<>$ denotes filtering has been applied. The differences between modelling experiments considering different processes are used to obtain the time-varying residual circulation due to isolated processes including interactive effects (Table 2). For a single process, the process residual obtained from model simulations is:

process residual $=$ full simulation-reduced simulation. 
Table 2 The model residuals hindcast by the POLCOMSGOTM-WAM (PGW) and POLCOMS-GOTM (PG) model, considering the following processes: meteorological forcing (M), baroclinicity (B), river flow (R), external residual (E), tides (T) and waves $(\mathrm{W})$. The processes included in each model residual and the interactions between processes affecting the residual are given

\begin{tabular}{llll}
\hline $\begin{array}{l}\text { Residual } \\
\text { identity }\end{array}$ & $\begin{array}{l}\text { Model runs subtracted } \\
\text { prior to filtering }\end{array}$ & $\begin{array}{l}\text { Process contribution } \\
\text { to the sub-tidal residual }\end{array}$ & $\begin{array}{l}\text { Process and } \\
\text { interaction } \\
\text { contribution to the } \\
\text { intra-tidal residual }\end{array}$ \\
\hline 1 & PG_T-nothing & $\mathrm{T}$ & - \\
2 & PGW_MBRETW-nothing & $\mathrm{M}, \mathrm{B}, \mathrm{R}, \mathrm{E}, \mathrm{W}, \mathrm{T}$ & $\mathrm{M}, \mathrm{B}, \mathrm{R}, \mathrm{E}, \mathrm{W}, \mathrm{T}$ \\
3 & PGW_MBRETW-PG_T & $\mathrm{M}, \mathrm{B}, \mathrm{R}, \mathrm{E}, \mathrm{W}$ & $\mathrm{M}, \mathrm{B}, \mathrm{R}, \mathrm{E}, \mathrm{W}, \mathrm{T}$ \\
4 & PG_MBRET-PG_BRET & $\mathrm{M}$ & $\mathrm{B}, \mathrm{R}, \mathrm{E}, \mathrm{T}, \mathrm{M}$ \\
5 & PG_MBRET-PG_MRET & $\mathrm{B}$ & $\mathrm{M}, \mathrm{R}, \mathrm{E}, \mathrm{T}, \mathrm{B}$ \\
6 & PG_MRET-PG_MET & $\mathrm{R}$ & $\mathrm{M}, \mathrm{T}, \mathrm{R}, \mathrm{E}$ \\
7 & PG_MBRET-PG_T-residuals 2,3 and 4 & $\mathrm{E}$ & $\mathrm{B}, \mathrm{R}, \mathrm{T}, \mathrm{E}$ \\
8 & PGW_MBRETW-PG_MBRET & $\mathrm{W}$ & $\mathrm{M}, \mathrm{B}, \mathrm{R}, \mathrm{E}, \mathrm{T}, \mathrm{W}$ \\
\hline
\end{tabular}

The sub-tidal residual and intra-tidal residual for that process are then defined as:

sub-tidal process residual

$=<$ full simulation-reduced simulation $>$,

intra-tidal process residual

$$
\begin{aligned}
= & (\text { full simulation }- \text { reduced simulation }) \\
& -<\text { full simulation }- \text { reduced simulation }>,
\end{aligned}
$$

For example, the metrological residual ( $\mathrm{M}$ in Table 2, row 4 ) is the difference between a full process model simulation (PGW_MBRET) and a reduced process simulation that does not include meteorology (PGW_BRET). Filtering this model residual removes any component with a coherent phase, thus removing interaction with intra-tidal frequency between the residual process itself and all other processes considered, mainly the tide. This method extracts the sub-tidal residual induced by the non-tidal process and its nonlinear interactions with other non-tidal forcing. The intra-tidal residual for meteorology is then obtained by subtracting the sub-tidal residual $(<$ PGW_MBRET-PGW_BRET $>$ ) from the process residual (PGW_MBRET-PGW_BRET). To obtain the non-tidal subtidal residual (Table 1, row 3, Figs. 4 and 5), the difference between a model full physics simulation containing all processes (PGW_MBRETW) and that of the tide only (PG_T) is filtered to remove all intra-tidal iteration.

In the "Results" section, the total (sub-tidal and intra-tidal) residual for one or more selected processes is obtained by subtracting a model simulation without the processes in question from one which includes them. The sub-tidal residual is obtained by filtering the total residual and the intra-tidal residual is calculated as the difference between the total and sub-tidal residual. By filtering the tide-alone ( $\mathrm{PG} \mathrm{T}$, residual 1) and the fully coupled (PGW_MBRETW, residual 2) model simulations, the sub-tidal ( $\geq 30 \mathrm{~h}$ ) tide-only and full process residual is obtained. This gives an idea of how the tide behaves within the modelled estuary and how it contributes compared with the non-tidal processes to the total residual circulation within the estuary channels.

\section{Results}

The following figures (Figs. 4, 5, 6, 7, 8, and 9) show the model data output on sigma levels transformed to depth contours. This transformation creates the semi-diurnal depth oscillation seen in the time variation of the vertical profile, especially near the surface and less so near the bed. This results from the squeezing and expansion of the vertical profile with tidally induced depth changes and should not be confused as tidal energy remaining in the signal. The transform from sigma to Cartesian coordinates allows the phase of the tide to be seen alongside the time-varying residual.

\section{Importance of the Tidally Generated Residual}

The modelled tide only (PG_T) and total circulation (PGW_MBRETW) are filtered to remove all semi-diurnal interaction to give the sub-tidal ( $\geq 30 \mathrm{~h}$ ) residuals. For these two cases, the much larger input signal to the filter causes the data loss at the ends of the time series to be over a longer period than for the weaker residual currents presented later (refer to "Model Validation" section). Comparison of these sub-tidal residuals determines the importance of the tide relative to the non-tidal processes in influencing the total residual circulation. Filtering the tide-alone simulation (PG_T) enables the tidal residual, generated by asymmetries and bathymetric constraint, to be obtained from the model. In both channels, the tide causes a long-term (time-averaged) two-layer horizontal structure (see Bolaños et al. 2013) due to the complexity of the bathymetry and Coriolis (Winant 2008; Zitman and Schuttelaars 2012). At the mooring locations, it is shown (Figs. 4 and 5) that the tide is dominant in the Welsh Channel creating a seaward flow, which varies with the spring-neap cycle in the major channel axis component 


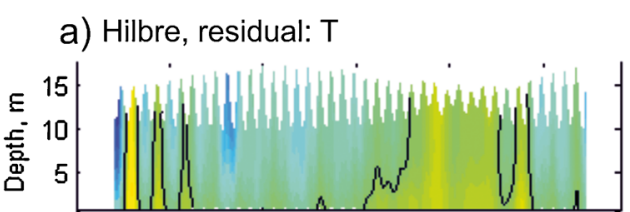

b) Hilbre, residual: T,M,B, R,E,W
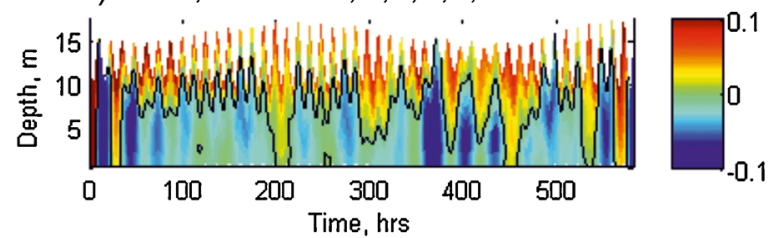

$\mathrm{ms}^{-1}$

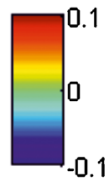

$-0.1$$$
\text { d) }
$$

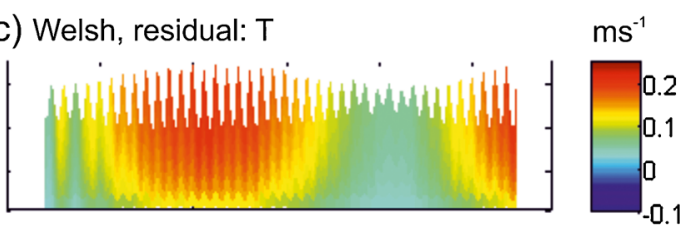

d) Welsh, residual: T,M,B, R,E,W

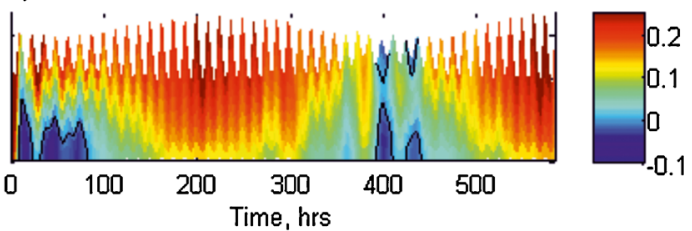

Fig. 4 The major channel axis sub-tidal component of the tidal (top - a, c) and total (bottom - b, d) residual for the Hilbre (left) and Welsh (right) channel mooring locations, Table 2, rows 1 and 2. The data are obtained at the modelled sigma levels and converted to depth above the bed to show

(Fig. 4c), while the major Hilbre Channel axis component (Fig. 4a) shows net landward flow during spring tide and net seaward flow during neaps. In both channels, the tidal residual is fastest towards the surface, which is most likely due to less frictional influence from the bed.

In the Hilbre Channel, the tidal time-mean flow is weak with seaward flow on the right and landward flow on the left with flow reversal occurring in the shallow regions towards both banks (Bolaños et al. 2013). The Hilbre mooring is situated to the left of the channel, when facing out to sea, so experiences a landward tidal time-mean flow. The time variation of this flow during different tidal ranges is likely to be in response to the shallow regions of flow reversal changing, and also to the weakening of the seaward sub-tidal tidal residual in the Welsh Channel during neap tides. In this channel, the tidal residual (Fig. 4a) is about half the magnitude of the sub-tidal residual generated by the combined non-tidal processes (Fig. 6a), considered in the next section. The influence of non-tidal processes on the total (tide plus nontidal) residual is therefore clearly seen (Fig. 4b).

In the Welsh Channel, a strong seaward flow occurs during spring tide, weakening to zero during neap tides (Fig. 4c). The a) Hilbre, residual: $T$

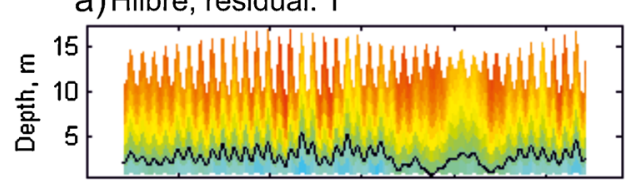

b) Hilbre, residual: T,M,B,R,E,W

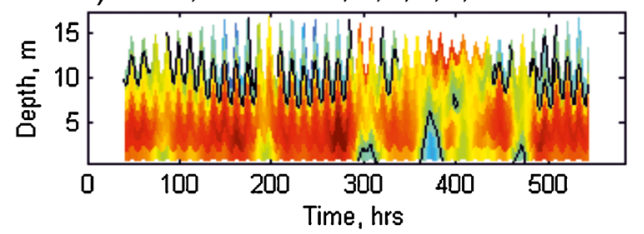

$\mathrm{ms}^{-1}$

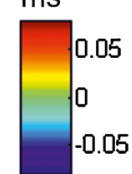

the tidal variation. The time axis starts at 06:00 14th February 2008. Positive flow is along the channel out of the estuary. The black contour line indicates the zero value contours

seaward direction of this flow is related to the mooring being located on the right side of the channel, when facing out to sea. The time-mean residual within the Welsh Channel has net outflow to the right and net inward flow to the left (Bolaños et al. 2013), with flow speeds more than double than that modelled in the Hilbre Channel. At spring tide, the magnitude of the Welsh tidal residual is much larger than that due to the non-tidal processes considered, thus greatly influencing the total (tide plus non-tidal) residual at this time (Fig. 4d). However, during neap tide, stronger stratification and therefore baroclinicity determines the residual pattern and not the tide, especially during calm atmospheric conditions ( $>75$ h, Fig. 4d). Storm impact, coinciding with neap tide, weakens the stratification modifying the total residual, which becomes storm process-driven ( $375-450$ h, Fig. $4 d)$.

The same effects as those seen in the major channel axis component occur in the minor channel axis component of both channels (Fig. 5). The Hilbre Channel has a complex sub-tidal residual in the minor channel axis component (Fig. 5b). The surface flow varies in direction from westerly due to baroclinic processes (see "The Sub-tidal Residual Contribution" section) to intense easterly during storm c) Welsh, residual: T

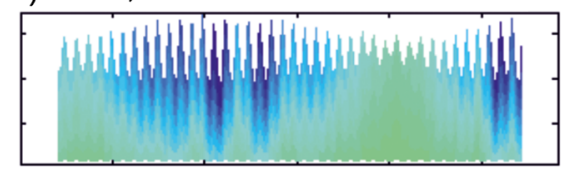

d) Welsh, residual: T,M,B,R,E,W

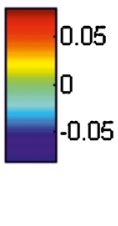

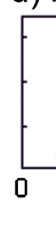

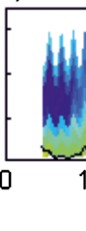

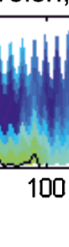

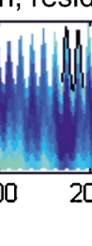

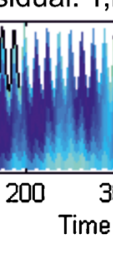

Fig. 5 The minor channel axis sub-tidal component of the tidal (top, a, c) and total (bottom, b, d) residual for the Hilbre (left) and Welsh (right) channel mooring locations, Table 2, rows 1 and 2 . The data are obtained at the modelled sigma levels and converted to depth above the bed to show the tidal variation. The time axis starts at 06:00 14th February 2008. In both channels, positive flow is across the channel from left to right when facing out of the estuary. The black contour line indicates the zero value contours 


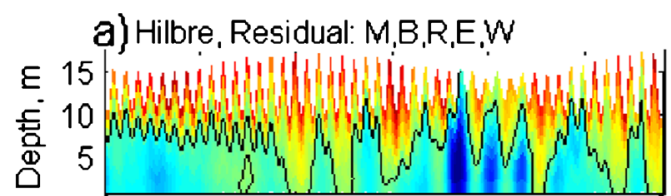

b) Hilbre, Residual: $M$

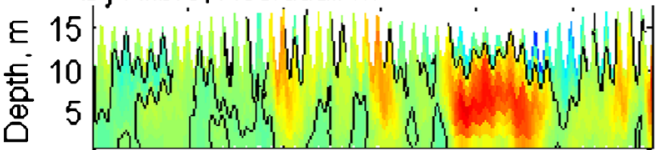

C) Hilbre, Residual: B

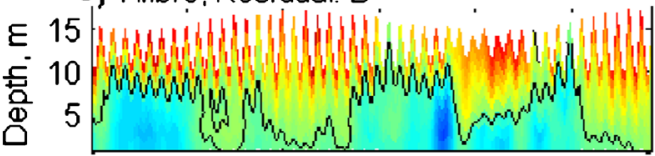

d) Hilbre, Residual: R.

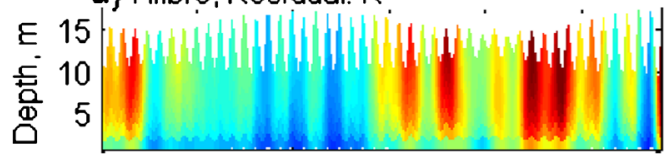

e) Hilbre, Residual: $\mathrm{E}$
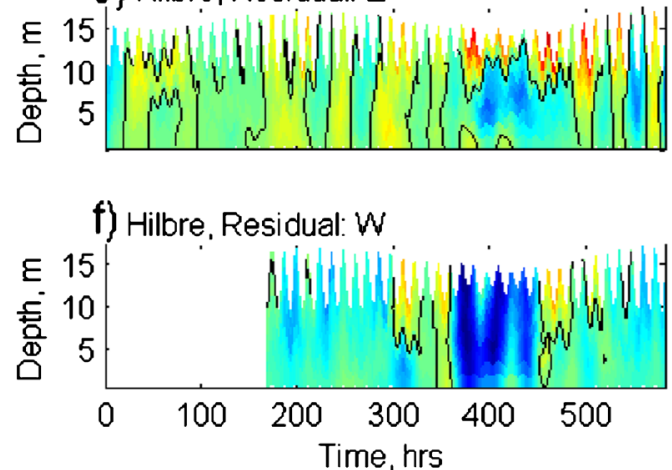

Fig. 6 The major channel axis sub-tidal component of the non-tidal model process residuals for the Hilbre (left, $\mathbf{a}-\mathbf{f})$ and Welsh (right, $\mathbf{g}-$ l) channel mooring locations. The processes considered are identified in Table 2, rows 3-8. The data are obtained at the modelled sigma levels and converted to depth above the bed to show the tidal variation. The time

conditions. However, the time-mean during calm conditions $(<192$ h, see Bolaños et al. 2013) of the total sub-tidal residual (Fig. 5b) is weakly towards the east due to wind influence. The balance between baroclinic and meteorological processes is therefore important (as suggested by the large Wedderburn number $>1.6$ calculated by Bolaños et al. 2013) when considering how the time-varying residual influences the long-term $3 \mathrm{D}$ circulation.

The Sub-tidal Residual Contribution

The non-tidal sub-tidal residuals (3- 8 given in Table 2 ) are analysed to determine the importance of different physical
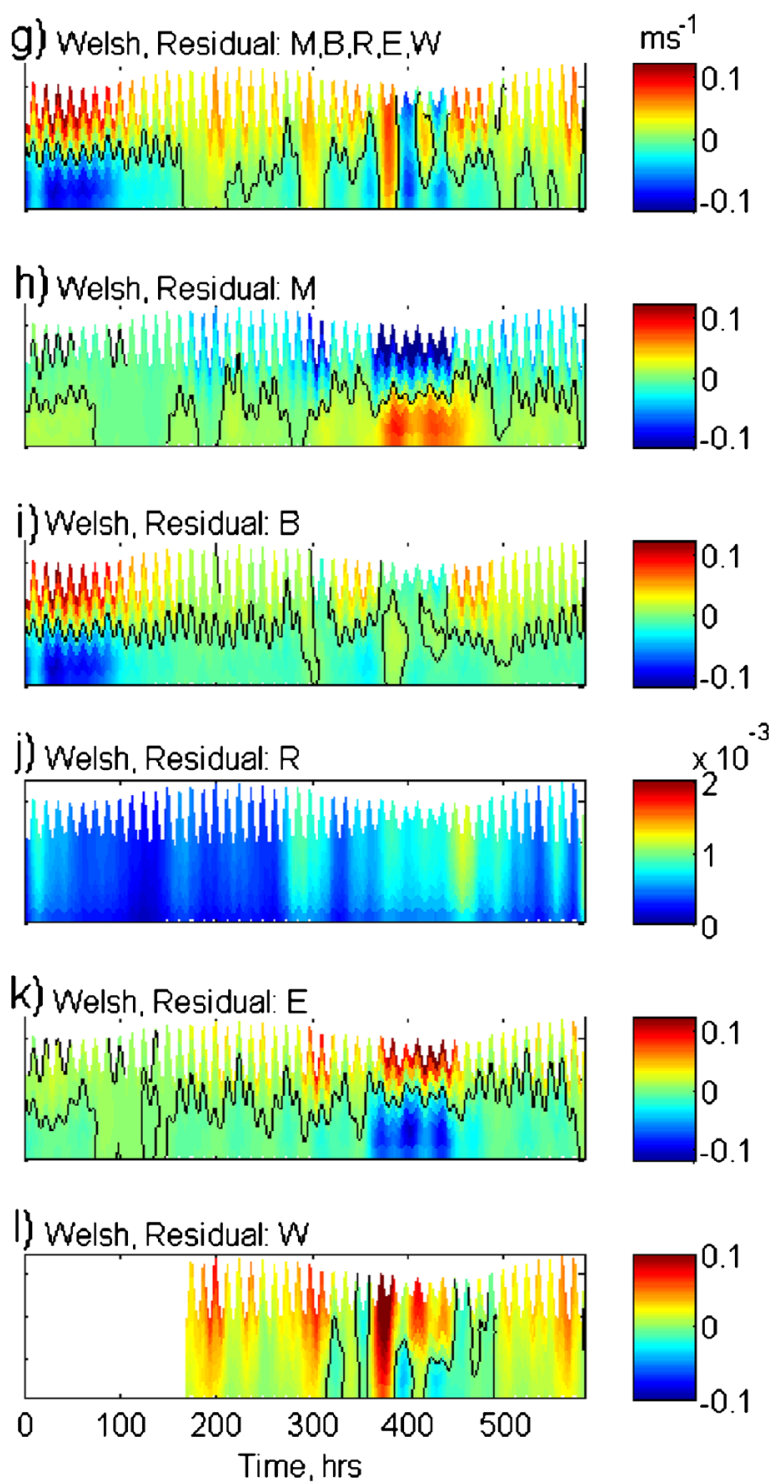

axis starts at 06:00 14th February 2008. Positive flow is along the channel out of the estuary. Note the different colour scale for the residual generated by the river discharge ( $\mathrm{R}$, case 6 in Table 2). The black contour line represents zero velocity

non-tidal processes, in contributing to the total residual circulation. In the Hilbre Channel, comparison of the non-tidal subtidal residual (Figs. 6a and 7a) with the total sub-tidal residual (Figs. $4 \mathrm{~b}$ and $5 \mathrm{~b}$ ) shows that non-tidal processes are dominant in both the major and minor channel components, since the subplots are near identical. In the Welsh Channel, the major channel axis component of non-tidal sub-tidal residual (Fig. 6g) is able to modify the total sub-tidal residual (Fig. 4d) during neap tides, while in the minor channel axis the non-tidal sub-tidal residual (Fig. $7 \mathrm{~g}$ ) continually influences the total sub-tidal residual (Fig. 5d), in the lower water column, in addition to influence over the full depth at neap tide, which is particularly strong during the storm event. 
Fig. 7 The minor channel axis sub-tidal component of the nontidal model process residuals for the Hilbre (left, $\mathbf{a}-\mathbf{f})$ and Welsh (right, $\mathbf{g}-\mathbf{l})$ channel mooring locations. The processes considered are identified in Table 2, rows 3-8. The data are obtained at the modelled sigma levels and converted to depth above the bed to show the tidal variation. The time axis starts at 06:00 14th February 2008. In both channels, positive flow is across the channel from left to right when facing out of the estuary. Note the different colour scale for the residual generated by the river discharge (R, case 6 in Table 2). The black contour line represents zero velocity
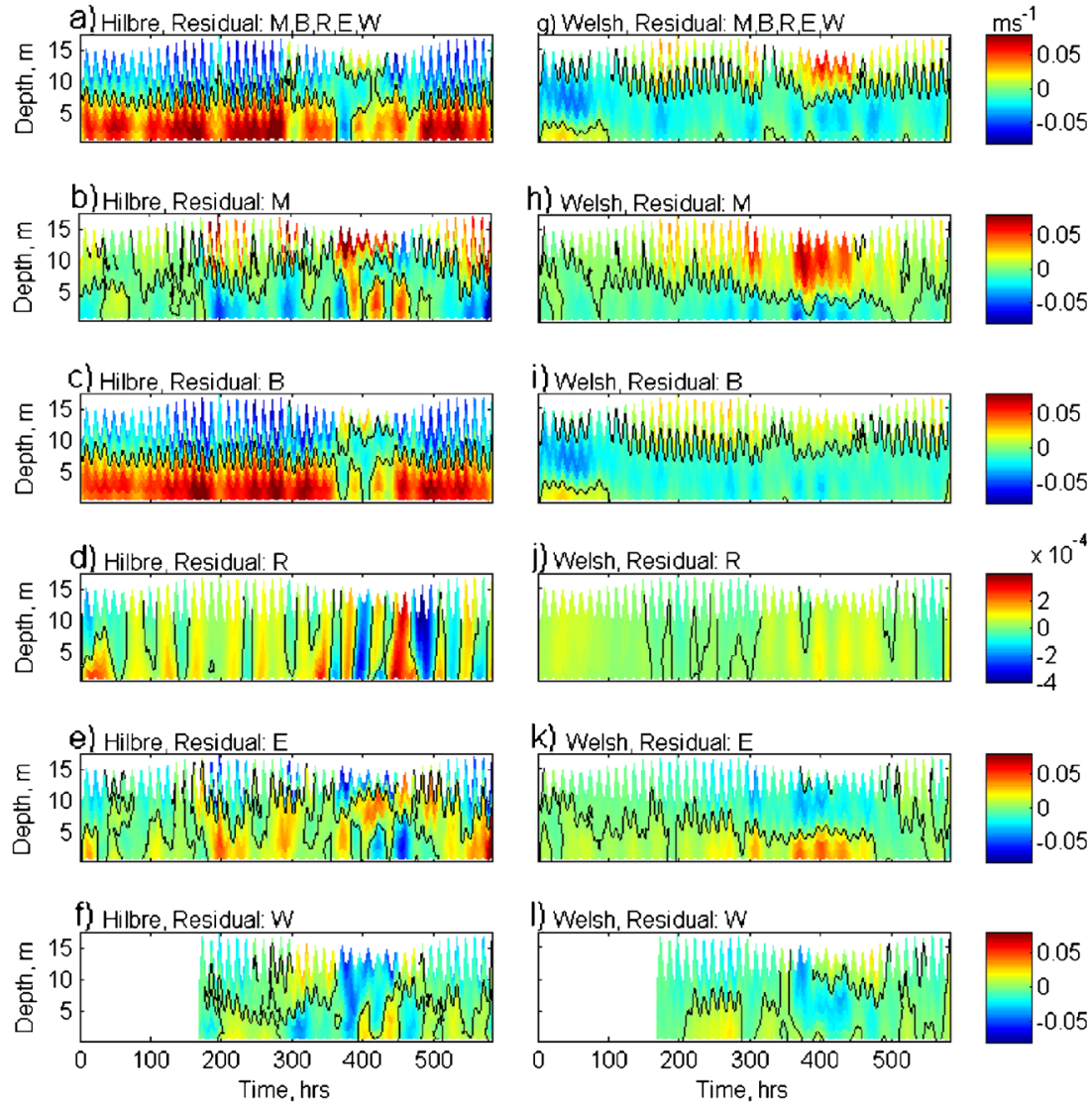

Figures 6 and 7 show that the non-tidal processes (considered in Table 2, rows 3-8) have greater influence in the Hilbre Channel, except for the external surge which has a similar influence in both. Baroclinicity (Figs. 6c and 7c) is the dominant process at generating sub-tidal residual circulation when all of the considered non-tidal processes are simulated together (Figs. 6a and 7a). This is seen clearly by the similarity in the time-varying pattern. It is important to recall that baroclinicity in this model application represents any process driven by density gradients and their straining. This creates a seaward surface flow and landward bottom flow in the major channel axis component (Fig. 6c). Even at high water, when the water column becomes mixed, straining continues to drive this circulation due to modifications in the flood tide velocity profile and turbulent mixing (Burchard and Baumert 1998), which interacts with the vertical profile of both the river flow and the seaward mass transport in response to Stokes' drift. The tidal straining induced residual therefore has similar characteristics to the classical density-driven flow (Burchard et al. 2011). In the major channel axis, the baroclinic residual component (Fig. 6c) is weakened following waves enhancing the seaward flow under windy conditions from the west, both processes reducing stratification (e.g. 300-320 h), or when the wind is southerly (e.g. $460 \mathrm{~h}$ ) and therefore opposing estuarine circulation. The depth of the baroclinic residual surface layer is also found to deepen during the extreme storm once the initially south-westerly winds have veered more westerly (e.g. 380-460 h).

In the Welsh Channel, the effect of baroclinicity is most noticeable during (neap) current-dominant conditions with southeast winds (the first $100 \mathrm{~h}$ of the study, Fig. 6i), even though the river discharge is low and decreasing. Under these conditions, stratification is able to form and is strengthened by wind straining. During the extreme storm event, the waves (359-447 h, Figs. 61 and 7l), external surge (captured in the external residual $\sim 400$ h, Figs. $6 \mathrm{k}$ and $7 \mathrm{k}$ ) and local meteorology (Figs. 6h and 7h) have the greatest influence. These processes weaken the stratification in the Welsh Channel and therefore also weaken the persistent density-driven flow pattern (Fig. 6i).

In both channels, the river discharge has the least influence (note the different color scale in Figs. $6 \mathrm{~d}, \mathrm{j}$ and $7 \mathrm{~d}, \mathrm{j}$ ) creating a weak offshore flow in both channels. The strength of this residual component is related to the river discharge entering the upper estuary from the catchment (Fig. 2e) and not the local storm event itself. Non-regular quasi-period oscillation is seen in the river flow at the mouth $(\geq 30 \mathrm{~h}$ ) due to interaction with the atmospheric forcing and possibly the long period variability in the channel cross-sectional area due to the surge component influencing the total water elevation over the intertidal shoals. The local meteorological (wind) forcing and the external surge seem to have counteractive effects at the event 
a) Hilbre, Residual: $M, B, R, E, W$

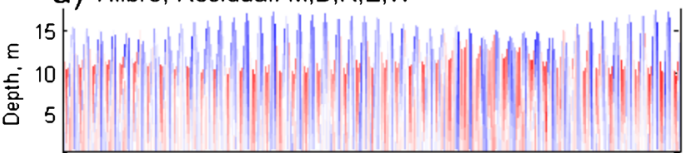

b) Hilbre, Residual: $M$

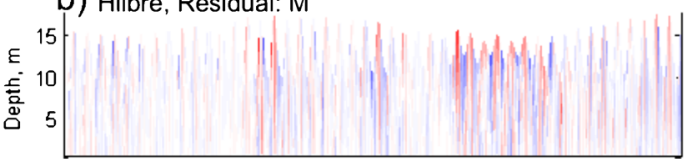

c) Hilbre, Residual: B
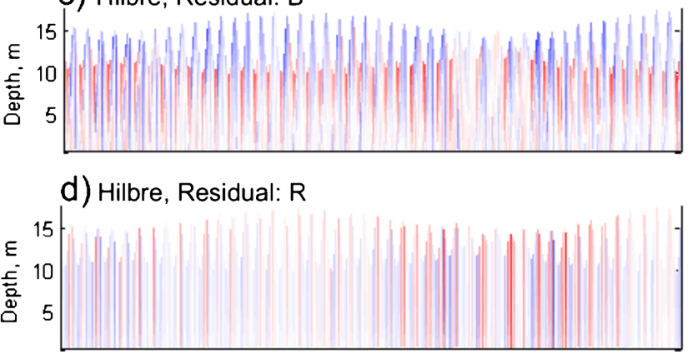

e) Hilbre, Residual: E
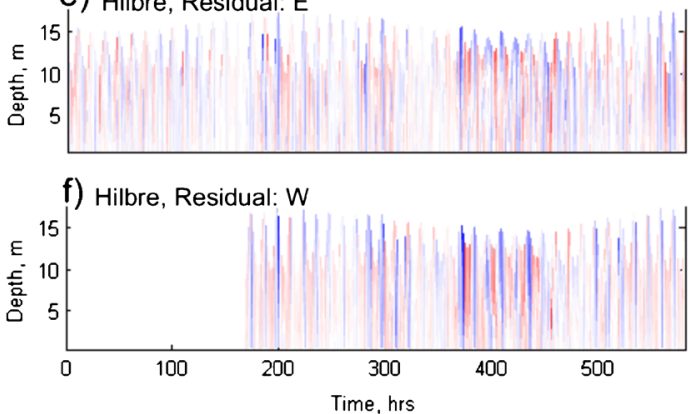

Fig. 8 The major channel axis component of the modelled intra-tidal residuals for the Hilbre (left, $\mathbf{a}-\mathbf{f})$ and Welsh (right, $\mathbf{g}-\mathbf{I}$ ) channel mooring locations. The non-tidal processes considered are identified in Table 2, rows 3-8. The data are obtained at the modelled sigma levels and converted to depth above the bed to show the tidal variation. The time

scale (compare Figs. 6b, $\mathrm{h}$ and $7 \mathrm{~b}$, h with Figs. 6e, $\mathrm{k}$ and $7 \mathrm{e}, \mathrm{k})$. The external surge acts to increase water levels causing flow into the estuary during southwest storm events, while the local southwest wind promotes seaward flow for the Hilbre Channel alignment. In the Welsh Channel, these two processes cause opposing bidirectional two-layer vertical residual flow structures. Finally, waves (Fig. 6f, 1), when present $(>168$ h, Fig. 2c), typically generate a landward flow in the Hilbre Channel and seaward flow in the Welsh Channel, although this trend reverses with seaward flow near the surface at times of weak southerly winds in the Hilbre Channel and with landward flow near the bed in the Welsh Channel at times of storm impact. The wave influence has vertical variability becoming more uniform with depth during the extreme storm period (360-470 h, often related to wind peaks in the Hilbre Channel and the peak wave height in the Welsh Channel). All these processes have clear short-term event-scale influence on the residual circulation.
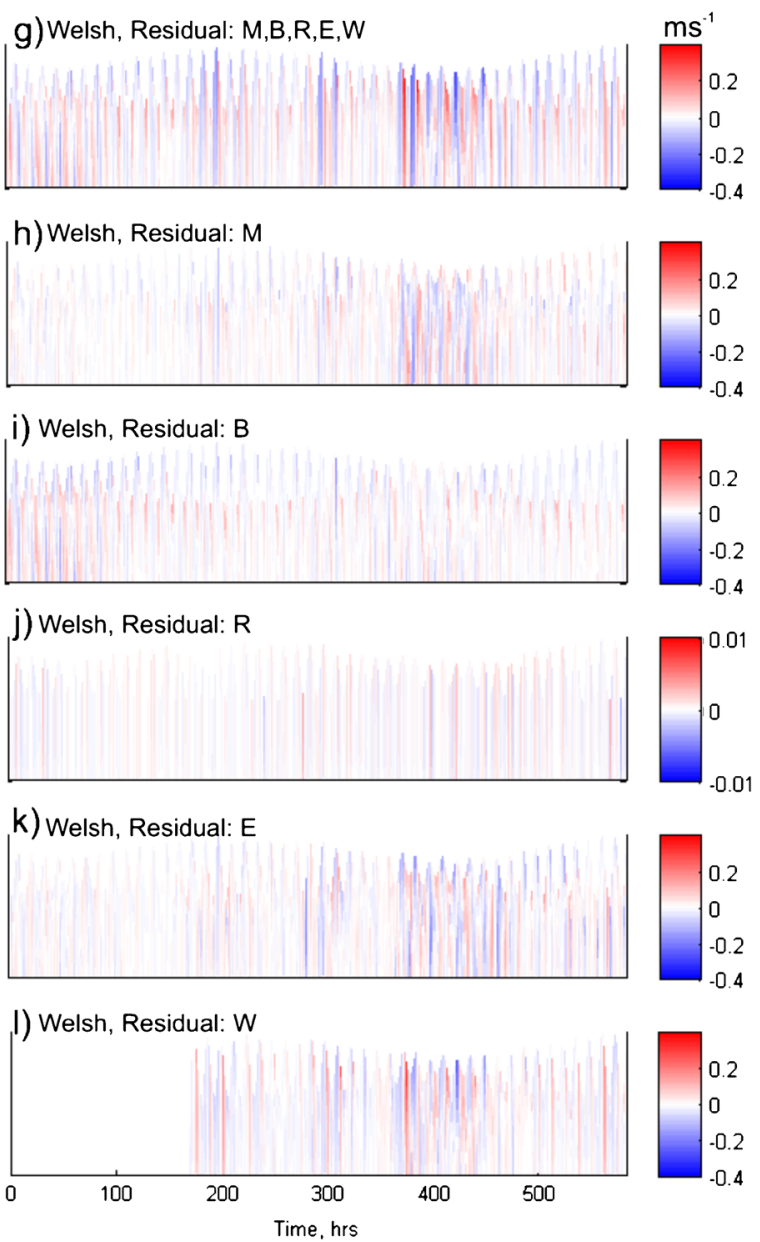

axis starts at 06:00 14th February 2008. Positive flow is an enhancement of the seaward and reduction of landward non-tidal process residual shown in Fig. 6 and vice versa for negative flow. Note the different colour scale for the residual generated by the river discharge (R, case 6 in Table 2)

The general pattern (Fig. 7a, g) in the minor channel axis residual component is driven by baroclinicity (Fig. 7c, i) and has an easterly bottom flow and westerly surface flow in the Hilbre Channel and a southerly bottom and northerly surface flow in the Welsh Channel. During storm conditions (e.g. 375-450 h), the stratification and therefore the minor channel axis baroclinic residual component become weaker and other non-tidal processes (local wind and less so waves) have a greater contribution to total nontidal residual.

The Intra-tidal Residual Contribution

The interactions within this hypertidal estuary are predominantly controlled by the tide. The intra-tidal residuals produced by tidal interactions are similar in magnitude to the sub-tidal residuals induced by the non-tidal processes; they are therefore equally as important in contributing to the total (subtidal plus intra-tidal) time-varying residual circulation. 
a) Hilbre, Residual: $M, B, R, E, W$

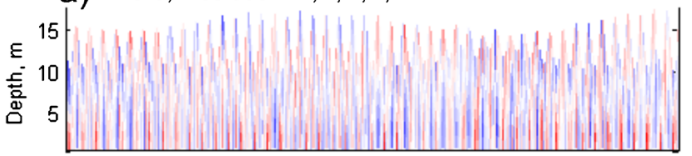

b) Hilbre, Residual: $M$

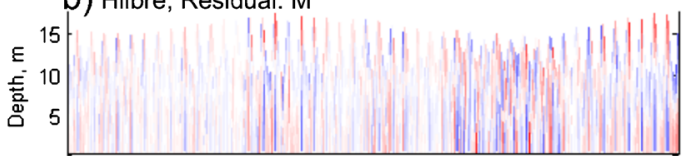

c) Hilbre, Residual: B
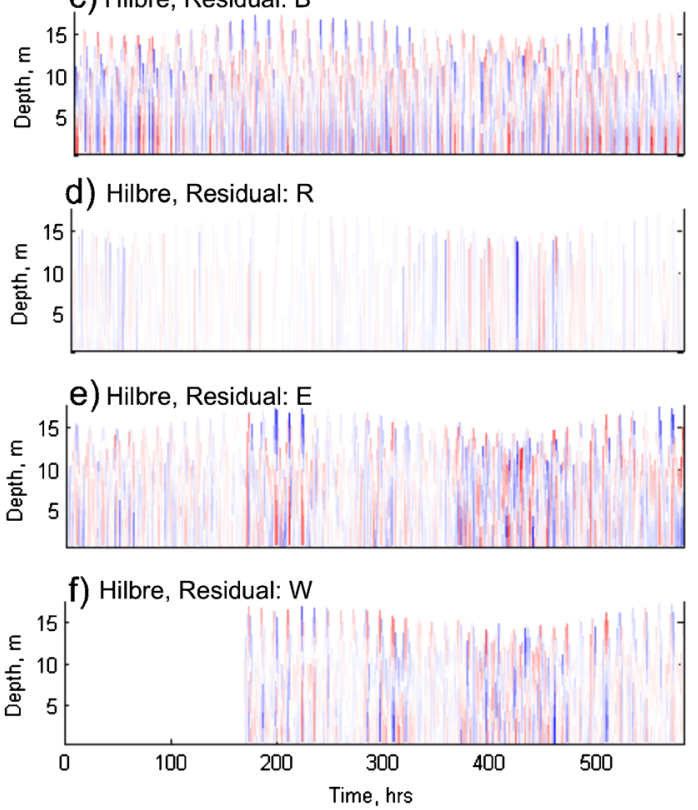

Fig. 9 The minor channel axis component of the modelled intra-tidal residuals for the Hilbre (left, $\mathbf{a}-\mathbf{f})$ and Welsh (right, $\mathbf{g}-\mathbf{I}$ ) channel mooring locations. The non-tidal processes considered are identified in Table 2, rows $3-8$. The data are obtained at the modelled sigma levels and converted to depth above the bed to show the tidal variation. The time

The non-tidal processes (3-8 given in Table 2), which have a greater influence in the Hilbre Channel, also cause a greater intra-tidal (interaction driven) residual within this channel (Figs. 8 and 9). The interactions generating the intra-tidal residual within Figs. 8 and 9 are given in Table 2 (column 4) and are not just due to the tide. Bolaños et al. (2013) show the importance of tide stratification interaction within this estuary, which enables periodic stratification to develop at low water followed by its breakdown creating a well-mixed water column at high water. Compared with the non-tidal sub-tidal residuals (Figs. 6 and 7), the intra-tidal residual (Figs. 8 and 9), although intermittent, is a significant contribution (at least double at times) to the total residual circulation generated by that process. The intra-tidal residual is of similar magnitude in both the major and minor channel axis components.

In the Hilbre Channel, all of the intra-tidal residuals are generally greater in the upper water column, suggesting tidally dominant interaction with magnitude related to the vertical tidal current profile. In this channel, the intra-tidal residual due g) Welsh, Residual: M,B,R,E,W

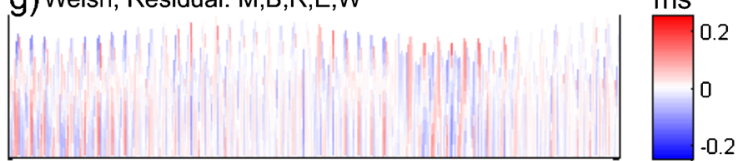

h) Welsh, Residual: $M$

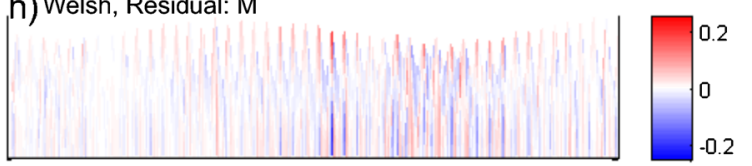

i) Welsh, Residual: $\mathrm{B}$

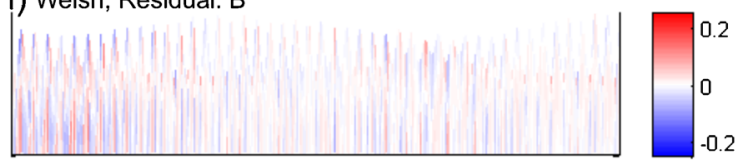

j) Welsh, Residual: $R$

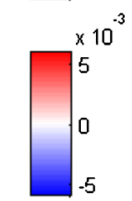

k) Welsh, Residual: E
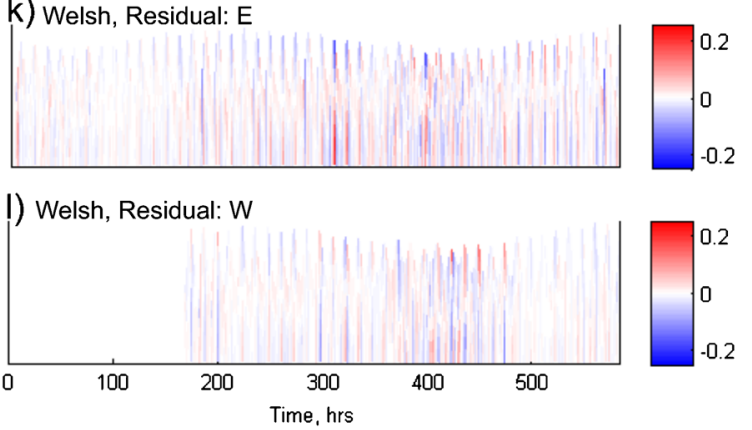

axis starts at 06:00 14th February 2008. Positive flow is an enhancement of flow towards the right of the channel and reduction of flow towards the left of the channel in the non-tidal process residual shown in Fig. 7 and vice versa for negative flow. Note the different colour scale for the residual generated by the river discharge (R, case 6 in Table 2)

to all the non-tidal processes (residual 3, Figs. 8a and 9a) is similar to that for baroclinicity in isolation (residual 5, Figs. $8 \mathrm{c}$ and $9 \mathrm{c}$ ), with additional storm process interaction contributing during the later part of the study period. Apart from the tide and baroclinicity, which have continuous interactive influence, the other processes have more intermittent interactions.

During the storm event, the local meteorology (wind, residual 4) interacts to create a seaward surface flow at high water elevations and landward surface flow at low water elevation (Figs. 8b and 9b). This interaction is clearly the result of wind straining. At high water slack, the estuarine stratification is weakest, but the wind fetches are greatest producing larger wind-induced currents. At low water slack, stratification is at its strongest, and the high wind speeds act to breakdown the two-layer system weakening the baroclinic residual circulation enabling the flood tide to have more influence on the surface layers. Strong stratification during low water slack increases the seaward surface flow due to the gravitational circulation. During the flood tide, the two-layer 
system is broken down, a landward flow occurs at the surface and continues at high water. The river flow (residual 6 , Figs. 8d and 9d) interacts with the tide causing a bidirectional flow residual at the mouth. An enhanced seaward flow is caused soon after high water during the ebb current. During low water, the river has a negligible influence in the Welsh Channel (Figs. 8j and 9j), but can cause a landward flow in the Hilbre Channel as the flood tide starts. At times of high river discharge, a second peak in seaward flow occurs around mid flood tide. In addition to this second seaward river pulse, a landward pulse occurs at mid ebb tide. These patterns are more clearly seen in the Hilbre Channel where the river discharge is strongest (e.g. intermittent red and blue stripes in Figs. $8 \mathrm{~d}$ and $9 \mathrm{~d}$, around $300-500 \mathrm{~h}$ ).

In both channels, the external residual (residual 7, Figs. $8 \mathrm{e}, \mathrm{k}$ and $9 \mathrm{e}, \mathrm{k}$ ) interacts during extreme events, in opposition to the wind. At high water elevations, a landward surface flow occurs, and at low water elevations, a seaward surface flow occurs. The higher water levels at the estuary mouth force more water into the estuary during the periods of weak stratification, which then leaves the estuary during lower water levels by enhancing the seaward surface flow as the two-layer structure forms. Wave interaction is greatest during wave events (residual 8, Figs. 8f, 1 and 9f, 1). Wave conditions are greatly controlled by the time-varying depth at the estuary mouth; wave-induced circulation is greatest at high water and is slightly stronger near the surface, causing flow into the estuary. At low water, the waves become restricted enabling the typical estuarine surface flow out of the estuary. There is a clear increase in the wave-driven current residual during the storm event (at 480 h, Figs. 8f, i and 9f, i).

In the Welsh Channel, the interaction for baroclinic processes (Figs. $8 \mathrm{i}$ and $9 \mathrm{i}$ ) and river flow (Figs. $8 \mathrm{j}$ and $9 \mathrm{j}$ ) shows the same patterns as those in the Hilbre Channel (Figs. 8c, d and $9 \mathrm{c}, \mathrm{d}$, for respective processes) but is weaker. The stormdriven processes are also weaker but generate the dominant interactive contribution in this channel. The meteorological intra-tidal residual is the only process which has a reversed influence in the Welsh Channel (Fig. 8h) compared with the Hilbre Channel (Fig. 8b). This is due to the channel orientation at the mooring location relative to the southwest wind direction, which drives seaward (northerly) flow in the Hilbre Channel and landward (easterly) flow in the Welsh Channel. Although the Welsh mooring is further towards the open coast, waves have weaker interactive nature with the tide, due to reduced sheltering, by the inter-tidal banks within the estuary, from the offshore wave activity.

\section{Discussion}

This paper extends the initial Dee study of Bolaños et al. (2013) to examine the influence of storm impact on the residual circulation, by continuing the study into a period of wave and current conditions. This paper investigates the event-scale time variation in the vertical residual velocity profile for both a baroclinic and barotropic estuary channel. This gives insight into how the processes interact under different conditions to produce a residual circulation and how the residual changes during different events, such as a wave event or series of neap tides. The 30-day time-mean of the residual is investigated by Brown et al. (2014) over perpendicular channel cross-sections. They compare equal periods of calm and stormy conditions to identify process dominance over the longer term, due to the cumulative effect of the event-scale process contribution (in magnitude and duration) presented here. The study period (Fig. 2) consists of calm and stormy conditions with a mean river discharge $\left(32 \mathrm{~m}^{3} \mathrm{~s}^{-1}\right)$, which is equivalent to the long-term mean $\left(31 \mathrm{~m}^{3} \mathrm{~s}^{-1}\right)$. This period therefore gives a good representation of the typical conditions within the Dee Estuary.

The dynamically evolving bathymetry within the Dee Estuary (Moore et al. 2009) and the lack of bathymetric data at the time of observation prevent the time-varying modelled circulation from being perfect at the single point of observation. In a hypertidal estuary, the large tidal prism means that inter-tidal shoals in addition to the sub-tidal channels will have an important role influencing the accuracy of the estuarine processes. In "The Modelling System" section, POLCOMS-GOTM is shown to give acceptable simulations of the residual circulation for the given input data (Fig. 3). Previously, the model has been found to be robust at modelling the $3 \mathrm{D}$ current patterns within Liverpool Bay (Brown et al. 2011; Palmer and Polton 2011) and the Dee (Bolaños et al. 2013). The model is therefore used to understand the contribution of different non-tidal physical processes to the time-varying residual current and also the importance of these processes compared with the tide. Although the model results are not a perfect resemblance of the limited observations, they do give insight into how estuarine processes interact within this system, demonstrating the important event-scale influence of storms and persistent influence of tidal interaction.

The presented findings are related to two isolated points, so they only give an indication of the residual processes within the studied estuarine channels. These results show that the event-scale residual circulation can at times differ from the long-term mean pattern (Brown et al. 2014) and the response to physical events is not consistent across the estuary. Calculation of the exchange flow (see MacCready 2011) within each channel and the time-mean salt exchange would enable further characterisation of this estuary by determining the residence time and river amplification factor compared with other systems.

The two studied tidal channels show very different timevarying characteristics. The Welsh Channel is dominated by 
the tidal residual during spring tide, with baroclinicity having secondary importance, becoming more noticeable during calm neap tide conditions. In this channel, extreme southwest storm events occurring at neap tide are able to modify the baroclinically induced residual at this time. However, periods of strong wind and high-wave conditions during spring tide have little impact on the dominant tidal residual. Periods of wave activity in the Welsh Channel have a large influence on the stratification, greatly reducing the baroclinically induced residual compared with current-dominant periods. This contrasts with the Hilbre Channel, in which baroclinicity, through strong straining, is of primary importance, except during extreme southwest storms when local wind has primary importance, and the tide is of a secondary importance. In this channel, the non-tidal processes play a much more important role to that of the tide. In the longer term, the total residual has a fairly consistent (15-day) time-mean pattern for both calm and stormy conditions (Brown et al. 2014). Events of increased wave activity seem to have less instantaneous influence, possibly due to the more sheltered position of the moored instruments within this channel.

During storm events, the induced process residuals are similar in magnitude to the more typical calm conditions. However, due to their short duration, storms are unlikely to have a great influence on the long-term residual pattern (Brown et al. 2014). The continuous atmospheric forcing, in particular wind, does influence the vertical (time-averaged) residual current profile (see Bolaños et al. 2013). The influence is greater in the minor channel axis component. For example, the time-varying Hilbre Channel surface residual has a long duration of baroclinic dominance during the study period, driving a weak westerly surface flow (Fig. 5c), while the short period storm event generates an easterly surface flow. However, the longer term (time average of Fig. 7b, Bolaños et al. 2013) surface residual is towards the east. Future changes in storminess could therefore act to modify the long-term 3D residual current patterns (which are shown by Brown et al. 2014), especially near the surface.

Strong tidal interaction with the non-tidal processes creates intra-tidal residuals of similar magnitude to the sub-tidal process residuals. This interaction distorts the time-varying residual, so filtering methods are required to clearly identify the sub-tidal process residuals. The difference in dominant processes between the two channels, the strength of the process interactions and spatial variability in the time-mean profile (see Bolaños et al. 2013) demonstrates the complexity of the flow within the estuary and the exchange at the mouth. This implies that the transport of suspended particles is not clearcut within this estuary. The mooring in the Welsh Channel was located towards the right side (when facing offshore), thus experiences one side of the horizontal two-layer structure (Bolaños et al. 2013). It is suggested that within the Welsh
Channel the ebb-dominant tidal residual causes a net export of sediment along the right side and is likely (although not studied here) to import sediment along the left side. Within the Hilbre Channel, a vertical two-layer structure (Bolaños et al. 2013), with landward bottom flow, is likely to import sediment. A study on bottom stress across the estuary domain for calm and stormy conditions (Bolaños et al. 2013) demonstrates that although the waves have little influence on the residual circulation, they will be an important mechanism for sediment resuspension. In the Welsh Channel where storm impact at neap tide can modify the overall residual circulation, the direction of wave-enhanced sediment transport could influence the net longer term sediment flux. The interaction of the tidally driven time variation in wave-driven resuspension, controlled by elevation and current direction, will add further complication to the net transport of sediment, which will be the subject of further studies.

\section{Conclusion}

Modelling enables the time-varying current residual, obtained at all vertical levels at any point within a study region, to be split into process components. Filtering then enables detailed information about the sub-tidal and intra-tidal process contribution to the total current residual to be extracted. This provides useful insight into the non-tidal time-varying process residuals in a hypertidal estuary. Here, the wave and circulation model (POLCOMS-GOTM-WAM) has been applied to the hypertidal Dee Estuary. The model has been validated and used to understand the time-varying current residual for the modelled bathymetry.

This estuary is known to have a dominant barotropic and baroclinic channel (Bolaños et al. 2013). However, at the event scale, the residual circulation is very variable and each channel is shown to respond differently to short-term forcing conditions. Non-tidal processes dominate the time-varying Hilbre Channel residual under all conditions, with baroclinicity consistently having a high contribution. Within the tidally dominant Welsh Channel, the time-varying residual is modified by baroclinicity during low energy conditions (neap tide and calm weather). The tidally dominant channel at the event scale (e.g. a period of neap tides) temporarily becomes baroclinically influenced. Storm-driven processes if coincidental with neap tides in this channel also modify the barotropic residual circulation. Storm impact at spring tide has not been captured by this study period. Extreme storms have a strong, but short-term influence during the event. In Liverpool Bay, extreme storm surges are often associated with southwest winds, under which conditions the local wind counteracts the influence of the external surge at this estuary's mouth. The influence of storm events on the residual circulation is different within the two channels due to their orientation relative to 
the wind direction. This is an example of how the complexity of the channel-bank system within an estuary prevents a consistent pattern in circulation occurring across the estuary. For sediment dynamics, the volume flux during such short-term events (e.g. storm events) of atypical circulation may have a high impact for the longterm net transport. The short-term deviations in residual circulation demonstrate that time-scales longer than seasonal influence (due to changes in storminess and river discharge) must be considered to truly define the longterm process dominance.

In addition to the sub-tidal residual, the interactions between tide and stratification are found to create a strong intra-tidal residual, influencing the time variation of the total residual. In hypertidal conditions, the interactions must also be included when considering residual circulation as they can be as important as the sub-tidal process contribution itself. The periodic (semi-diurnal for the Hilbre Channel and during calm neap conditions for the Welsh Channel) formation of the vertical two-layered water column structure can have an important role in longer term transport pathways. It is therefore suggested that the net transport of suspended and dissolved particles within a hypertidal estuary system can be dependent on the baroclinicity despite low river flow. Management issues related to long-term fluxes and net transport therefore require careful consideration of the baroclinic influence, even within hypertidal systems. To properly determine residual fluxes at any point within an estuary, the full cross-section of the estuary must also be considered. The analysis of MacCready (2011) would be a suitable method to calculate the volume flux through an estuary mouth.

Acknowledgments The authors would like to thank the reviewers of this manuscript for their very thorough comments helping to focus the content. This research has been carried out as part of Ocean 2025, FORMOST (NERC grant NE/E015026/1), FIELD_AC (EU FP7 program grant 242284) and iCOASST (NERC grant NE/J005444/1). The support of the European Commission through FP7, Contract 288710 MERMAID ("Innovative Multi-purpose offshore platforms: planning, design and operation"), is also acknowledged. John Howarth's help with using low-pass filters was greatly received. Jane Williams (NOC) is thanked for providing the operational surge model output and meteorological (wind and pressure) data, while Clare O'Neill (NOC, COBS) is thanked for providing the offshore temperature and salinity fields to the Irish Sea and supplementing the meteorological forcing with air temperature, humidity and cloud cover to enable full atmospheric forcing. River data has also been supplied by the Centre for Ecology and Hydrology (CEH) from the UK National River Flow Archive, consisting of the Environment Agency (EA) gauging stations, for the river flow rates around the Irish Sea.

Open Access This article is distributed under the terms of the Creative Commons Attribution License which permits any use, distribution, and reproduction in any medium, provided the original author(s) and the source are credited.

\section{References}

Aubrey, D.G., and P.E. Speer. 1985. A study of non-linear tidal propagation in shallow inlet/estuarine systems, part 1: observations. Estuarine, Coastal and Shelf Science 21: 185-205.

Bolaños, R., and A. Souza. 2010. Measuring hydrodynamics and sediment transport processes in the Dee Estuary. Earth Systems Science Data 2: 157-165.

Bolaños, R., J.M. Brown, and A. Souza. 2011. Three dimensional circulation modeling in the Dee Estuary. Journal of Coastal Research SI 64: 1457-1461.

Bolaños, R., J.M. Brown, L.O. Amoudry, and A.J. Souza. 2013. Tidal, riverine and wind influences on the circulation of a macrotidal estuary. Journal of Physical Oceanography 43(1): 29-50.

Boon, J.D., and R.J. Byrne. 1981. On basin hyposmetry and the morphodynamic response of coastal inlet systems. Marine Geology 40(1-2): 27-48.

Bowers, D.G., and A. Al-Barakati. 1997. Tidal rectification on drying estuarine sandbanks. Estuaries 20(3): 559-568.

Brown, J.M. 2010. A case study of combined wave and water levels under storm conditions using WAM and SWAN in a shallow water application. Ocean Model 35(3): 215-229.

Brown, J.M., and A.G. Davies. 2010. Flood/ebb tidal asymmetry in a shallow sandy estuary and the impact on net sand transport. Geomorphology 114(3): 431-439.

Brown, J.M., A.J. Souza, and J. Wolf. 2010. An 11-year validation of wave-surge modelling in the Irish Sea, using a nested POLCOMSWAM modelling system. Ocean Model 33(1-2): 118-128.

Brown, J.M., R. Bolaños, and J. Wolf. 2011. Impact assessment of advanced coupling features in a tide-surge-wave model, POLCOMS-WAM, in a shallow water application. Journal of Marine Systems 87(1): 13-24.

Brown, J.M., R. Bolaños, M.J. Howarth, and A. Souza. 2012. Extracting sea level residual in tidally dominated estuarine environments. Ocean Dynamics 62(7): 969-982.

Brown, J.M., L.O. Amoudry, F.M. Mercier, and A.J. Souza. 2013a. Intercomparison of the Charnock and COARE bulk wind stress formulations for coastal ocean modelling. Ocean Science 9(4): 721-729.

Brown, J.M., R. Bolaños, and J. Wolf. 2013b. The depth-varying response of coastal circulation and water levels to 2D radiation stress when applied in a coupled wave-tide-surge modelling system during an extreme storm. Coastal Engineering 82: 102-113.

Brown, J., R. Bolaños and A. Souza. 2014. Controls on the medium term estuarine residuals: circulation and elevation. Ocean Dynamics, special issue: PECS 2012: Physics of Estuaries and Coastal Seas, New York, USA, 12-16th August 2012.

Burchard, H. 2009. Combined effects of wind, tide, and horizontal density gradients on stratification in estuaries and coastal seas. Journal of Physical Oceanography 39(9): 2117-2136.

Burchard, H., and H. Baumert. 1998. The formation of estuarine turbidity maxima due to density effects in the salt wedge. A hydrodynamic process study. Journal of Physical Oceanography 28(2): 309-321.

Burchard, H., and R.D. Hetland. 2010. Quantifying the contributions of tidal straining and gravitational circulation to the residual circulation in periodically stratified tidal estuaries. Journal of Physical Oceanography 40(6): 1243-1262.

Burchard, H., R.D. Hetland, E. Schulz, and H.M. Schuttelaars. 2011. Drivers of residual estuarine circulation in tidally energetic estuaries: straight and irrotational channels with parabolic cross section. Journal of Physical Oceanography 41(3): 548-570.

Chen, S.-N., L.P. Stanford, and D.K. Ralston. 2009. Lateral circulation and sediment transport driven by axial winds in an idealized, partially mixed estuary. Journal of Geophysical Research 114, C12006. $18 \mathrm{pp}$. 
Hansen, D.V., and M. Rattray. 1965. Gravitational circulation in straits and estuaries. Journal of Marine Research 23: 104-122.

Holt, J.T., and I.D. James. 2001. An s coordinate density evolving model of the northwest European continental shelf: 1, model description and density structure. Journal of Geophysical Research 106(C7): 14,015-14,034.

Huthnance, J.M. 1981. On mass transports generated by tides and long waves. Journal of Fluid Mechanics 102: 367-387.

Komen, G.J., L. Cavaleri, M. Donelan, K. Hasselmann, S. Hasselmann, and P.A.E.M. Janssen. 1994. Dynamics and modelling of ocean waves. Cambridge: Cambridge University Press. $532 \mathrm{pp}$.

Longuet-Higgins, M.S. 1958. The mechanisms of the boundary layer near the bottom in a progressive wave. Proceedings of the 6th international conference on coastal engineering, 184-193.

Longuet-Higgins, M.S. 1970. Longshore currents generated by obliquely incident sea waves, 1. Journal of Geophysical Research 75(33): 6778-6789.

Longuet-Higgins, M.S., and R.W. Stewart. 1964. Radiation stresses in water waves; a physical discussion, with applications. Deep-sea Research 11: 529-562.

MacCready, P. 2011. Calculating estuarine exchange flow using isohaline coordinates*. Journal of Physical Oceanography 41(6): 1116-1124.

Mellor, G. 2003. The three-dimensional current and surface wave equations. Journal of Physical Oceanography 33(9): 1978-1989.

Mellor, G. 2005. Some consequences of the three-dimensional current and surface wave equations. Journal of Physical Oceanography 35(11): 2291-2298.

Monbaliu, J., R. Padilla-Hernández, J.C. Hargreaves, J.C. CarreteroAlbiach, W. Luo, M. Sclavo, and H. Günther. 2000. The spectral wave model WAM adapted for applications with high spatial resolution. Coastal Engineering 41(1-3): 41-62.

Monismith, S.G., J. Burau, and M. Stacey. 1996. Stratification dynamics and gravitational circulation in northern San Francisco Bay. In San Francisco Bay: The Ecosystem, ed. T. Hollibaugh, 123-153. San Francisco: American Association for the Advancement of Science.

Moore, R.D., J. Wolf, A.J. Souza, and S.S. Flint. 2009. Morphological evolution of the Dee Estuary, Eastern Irish Sea, UK: a tidal asymmetry approach. Geomorphology 102(4): 588-596.

Palmer, M.R., and J.A. Polton. 2011. A strain induced freshwater pump in the Liverpool Bay ROFI. Ocean Dynamics 61(11): 1905-1915.
Polton, J.T., M.R. Palmer, and M.J. Howarth. 2013. The vertical structure of time-mean estuarine circulation in a shallow, rotating, semi-enclosed coastal bay: a Liverpool Bay case study with application for monitoring. Continental Shelf Research 59: 115126.

Prandle, D. 2004. Review: how tides and river flows determine estuarine bathymetries. Progress in Oceanography 6: 1-26.

Pritchard, D.W. 1952. Salinity distribution and circulation in the Chesapeake Bay estuarine system. Journal of Marine Research 15: 33-42.

Pye, K. 1996. Evolution of the shoreline of the Dee Estuary, United Kingdom. In Estuarine shores: evolution, environments and human alterations, ed. K.F. Nordstrom and C.T. Roman, 14-37. New York: Wiley.

Simpson, J.H., J. Brown, J. Matthews, and G. Allen. 1990. Tidal straining, density currents, and stirring in the control of estuarine stratification. Estuaries 13(2): 125-132.

Souza, A.J. 2013. On the use of the Stokes number to explain frictional tidal dynamics and water column structure in shelf seas. Ocean Science 9: 391-398.

Umlauf, L., and H. Burchard. 2005. Second-order turbulence closure models for geophysical boundary layers. A review of recent work. Continental Shelf Research 25(7-8): 795-827.

Wang, B., O.B. Fringer, S.N. Giddings, and D.A. Fong. 2009. Highresolution simulations of a macrotidal estuary using SUNTANS. Ocean Model 26(1-2): 60-85.

Warner, J.C., D.H. Schoellhamer, C.A. Ruhl, and J.R. Burau. 2004. Floodtide pulses after low tides in shallow subembayments adjacent to deep channels. Estuarine, Coastal and Shelf Science 60(2): 213 228.

Willmott, C.J., S.G. Ackleson, R.E. Davis, J.J. Feddema, K.M. Klink, D.R. Legates, J. O'Donnell, and C.M. Rowe. 1985. Statistics for the evaluation and comparison of models. Journal of Geophysical Research 90(C5): 8995-9005.

Winant, C.D. 2008. Three-dimensional residual tidal circulation in an elongated, rotating basin. Journal of Physical Oceanography 38(6): $1278-1295$.

Zitman, T.J., and H.M. Schuttelaars. 2012. Importance of cross-channel bathymetry and eddy viscosity parameterisation in modeling estuarine flow. Ocean Dynamics 62(4): 603-631. 